\title{
Sobre los orígenes históricos del bipartidismo en norteamérica*
}

\section{Guillermo Zermeño}

\begin{abstract}
"Our democracy is but a name. We vote? What does mean? It means that we choose between two bodies of real, though not avowed, autocrats. We choose between tweedledum and tweedledee..."
\end{abstract}

(Helen Keller a un sufragista inglés, 1911)'

E I sistema político norteamericano ha sido tradicionalmente definido como un sistema bipartidista, propuesto además como modelo democrático ideal para otras regiones del mundo. ${ }^{2}$ En relación al concepto de democracia la gran mayoría de los estudiosos coinciden en definirla "como un sistema de gobierno parlamentario en el cual existe una base universal, o casi universal, de sufragio, la ocupación de cargos no está restringida a una clase limitada, de crítica acerca de las medidas políticas del gobierno se tolera y toma una forma institucional en uno o varios partidos de oposición, y existen sanciones legales formales adecuadas para proteger a esa crítica". ${ }^{3}$

Dadas estas características no es gratuito que los liberales mexicanos del siglo XIX idealizaran las instituciones políticas y la sociedad norteamericana. por lo menos hasta antes de la Reforma. ${ }^{4}$

Habría que añadir, sin embargo, que publicistas expertos se han encargado además de maquillar cuidadosamente su modelo de democracia, a fin de no dejar ver, en dado caso, su deterioro o envejecimiento.

Sólo con la aparición de los grandes monopolios industriales y financieros y las primeras intervenciones imperialistas de los Estados Unidos a finales del siglo XIX la conciencia liberal entra en crisis. Serán los historiadores progresistas, como Charles A. Beard, los que se encargarán de minar el mito de la democracia liberal norteamericana.

Uno de los puntales de esta democracia lo constituye el bipartidismo. Es

El presente ensayo es la ponencia corregida, en alguna de sus partes ampliada. que se presentó en el Instituto Mora en una mesa redonda sobre el tema de la "Evolución del sistema político en los Estados Unidos de América". Fue realizada con la intención de ofrecer un panorama general del desarrollo histórico del bipartidismo norteamericano y de proporcionar algunas ideas que permitieran explicar su origen y su peculiar desarrollo. En rigor no constituye una aportación totalmente original: gran parte de las ideas aquí expuestas pertenecen a autores como Charles A. Beard y Richard Hofstadter, dos historiadores cuyos aportes para la comprensión crítica de la historia norteamericana han sido de gran relevancia.

1 Citada por Howard Zinn. A People's History of the United States, Nueva York. Harper Colophon Books, 1980, p. 337.

2 El concepto de sistema de partidos fue desarrollado por: William N. Chambers, Political Parties in a New Nation. Nueva York, s.e., 1963. El autor concluye que Estados Unidos fue el inventor del primer sistema de partidos políticos en el mundo. Sugiere que este invento de fines del siglo XVIII se convirtió en un modelo útil para las nuevas naciones asiáticas y africanas que alcanzaron su independencia en la década que se inicia en 1960.

3 Richard Hofstadter, Los historiadores progresistas. Buenos Aires. Paidós. 1968, p. 126.

4 Charles A. Hale, El liberalismo mexicano en la época de Mora, 1821 -1853. México. siglo XXI, 1972, p. 193. 
bastante conocido que su juego cobra mayor importancia a nivel local que nacional. Por otro lado es para muchos una interrogante que este bipartidismo no se haya visto amenazado seriamente por un tercer partido. La respuesta tiene que ver con el consenso que se crea en torno a los fundadores de la nación norteamericana $y$ a cuya presentación nos remitiremos más abajo. Por ahora basta decir que este acuerdo ideológico es un factor fundamental de la estabilidad del sistema, pero que permanece inexplicable si se le aísla de la aparición histórica del moderno capitalismo industrial. De alguna manera Marx y Engels ya lo vislumbraban cuando escribian en el Manifiesto que "la burguesía, después del establecimiento de la gran industria y del mercado universal, conquistó finalmente la hegemonía exclusiva del poder político en el Estado representativo moderno. El Gobierno del Estado moderno no es más que una junta que administra los negocios comunes de toda la clase burguesa". ${ }^{5}$ En el caso norteamericano, cuando se habla de basar el gobierno de la nación en el consenso del pueblo, éste se refiere a los "pequeños terratenientes". Así, aptos para el sufragio serían aquéllos que "estuviesen en condiciones de intereses permanentes con la sociedad, y la firmeza de los lazos que a ella se ligaban", o sea, aquéllos que poseyeran bienes suficientes. ${ }^{6}$ En estos términos un aparato como éste no podía fomentar ideas que llegaran a ser "hostiles hacia sus presupuestos fundamentales de funcionamiento". Continúa Richard Hofstadter, tales ideas podrán aparecer pero estarían destinadas a sufrir un proceso de aislamiento hasta ser confinadas a grupos reducidos de intelectuales disidentes, $y$. "excepto en tiempos de agitación social" podrían circular entre los políticos en activo. ${ }^{7}$

La idea de esta clase de "consenso" sugiere ya los límites de esta lucha bipartidista. En la práctica, como se verá más adelante al presentar un esbozo de periodización, se verá que un mismo partido ha mantenido el control político por largos periodos de tiempo. Asimismo, al revisar su origen histórico alrededor de los debates sobre la redacción y ratificación de la constitución (1787-1789), se observará que la ambivalencia del texto constitucional así querida por sus redactores, deja las puertas abiertas tanto para el establecimiento del juego de partidos como para el control del gobierno por uno solo. ${ }^{8}$ La participación pluralista presentada sobre la base de igualdad y libertad sólo refleja las condiciones formales sobre las que se opera el intercambio de mercancías, ámbito en el que sólo formalmente se da el intercambio no desigual entre propietario y no propietario. entre capitalista y trabajador. ${ }^{9}$ Se puede hablar entonces de juego bipartidista pero en un marco consensual "unipartidista".

Si entendemos por partido político una estructura social amplia que cumple la función de mediar entre la opinión pública y las decisiones que se toman en el parlamento, se puede aceptar con Hofstadter que es en Estados Unidos donde aparece por primera vez el juego bipartidista durante la época del presidente Andrew Jackson (1824-1836). Antes de estas fechas resulta problemático hablar de partidos políticos, ya que los partidos que surgen durante la primera administración del presidente George Washington se pare-

5 Carlos Marx y Federico Engels. "Manifiesto del Partido Comunista" en Obras Escogidas, Moscú, Progreso, 1955, vol. I, p. 22 (2 vols.)

- R. Hofstadter, La tradición política norteamericana y los hombres que la formaron. Barcelona, Seix-Barral, 1969. p. 26.

7 Ibidem, p. 9

s Véase: John Critenden. Parties and Elections in the United States, s.t., Prentice Hall, 1982, p. 11

9 Cfr. Stanley Moore, Crítica de la democracia capitalista, México, Siglo XXI, 1981, (6a. edición).p. 70 . 
cer más a los partidos ingleses del siglo XVIII, es decir, son grupos de opinión diversos en torno a la interpretación de la constitución, con la salvedad que en los Estados Unidos se da por primera vez en 1800 la transición pacífica del poder entre un grupo político y otro. Sin embargo lo anterior no se entiende si no se advierte que pese a que entonces prevalecen fuertes sentimientos en contra de la formación de partidos, muchos de los que se resisten a la idea participarán, no obstante, activamente en la formación del primer sistema de partidos. En palabras de Hofstadter, estos hombres liegan a ser "antiparty party builders". Así, pese a que en 1800 se efectúa por primera vez la transición pacífica del poder de unas manos a otras, la aceptación general de la idea de una oposición legítima no ocurrirá sino hasta mucho después, en el periodo de Andrew Jackson, ${ }^{10}$ época en la que el partido demócrata se convierte en un partido de masas, o en términos de Max Weber, en una organización patrocinadora de cargos, "en cuyo caso su objetivo consiste sencillamente en llevar a sus jefes por medio de elecciones al lugar director, para que éstos distribuyan luego los cargos estatales entre su séquito, 0 sea entre el aparato burocrático y de propaganda del partido".".1

A continuación se hará una breve periodización de las distintas fases del bipartidismo norteamericano en su continuidad y discontinuidad, y después se presentará una caracterización de los dos primeros sistemas, mismos que tienen que ver, el primero con el surgimiento de Estados Unidos como nación independiente, $y$ el segundo, con su desarrollo expansionista e imperialista.

Generalmente historiadores y politólogos norteamericanos aceptan un tipo de periodización del sistema bipartidista que, con pequeñas modificaciones, puede comprender cinco etapas. La primera se refiere al predominio del partido federalista de Alexander Hamilton y al surgimiento propiamente del bipartidismo, es decir, a la aparición de un partido de oposición; el segundo sistema de partidos, como prefieren llamarlo algunos autores, está determinado por el triunfo del partido demócrata de Andrew Jackson - continuador del republicano jeffersoniano - y por la aparición de un nuevo partido de oposición denominado nacional republicano, poco más tarde llamado Whig. relevo o continuador de los ideales federalistas. Durante el tercer sistema, en los umbrales de la guerra civil, los whigs, ahora bajo el nombre de republicanos como hoy en día se les conoce, toman la delantera a los demócratas que en ese momento están dominados por los líderes esclavistas del sur. El partido republicano saldrá triunfante de la contienda armada y dominará la escena política nacional hasta los años de la depresión del 29. Salvo los cuatro periodos presidenciales de Grover Cleveland y de Woodrow Wilson, el resto está dominado por presidentes republicanos. Esta fase contiene además el hecho fundamental para poder entender los cambios ocurridos en el siglo xx: la transición del capital agrícola-industrial al capital financiero, el fin de la era expansionista norteamericana y el comienzo de la imperialista en las postrimerías del siglo $\mathrm{XIX} .^{12}$

10 Estas ideas están tomadas de la obra de: Richard Hofstadter. Ideas of a party system: The rise of legitimate oppositon in the U.S., 1780-1840. Berkeley, 1969. Además existe una exposición sintética en su artículo "Los partidos politicos", de la obra editada por C. Vann Woodward. Historia comparada de los Estados Unidos, México. Elsa. 1971, p. 214-228.

1 Max Weber, Economía y Sociedad. México. FCE, 1983, (6a. reimpresión). p. 1078.

12 Corresponde al primer Roosevelt la tarea de tratar de armonizar el capitalismo liberal con el capitalismo monopólico. 
La crisis financiera de los años treinta de este siglo no resuelta por los republicanos, conduce a la preponderancia demócrata en la figura del segundo Roosevelt. En esta cuarta etapa se estructura un proyecto, el "New Deal", de restauración del capitalismo, cuyo resultado es el llamado "estado de bienestar". La terminación de este proyecto cuyos síntomas de deterioro comienzan a aparecer a fines de los cincuentas, pero se evidencian en la siguiente década, señala el inicio de la quinta etapa del sistema bipartidista que reporta el comienzo de una crisis del sistema global norteamericano, y que se prolonga hasta nuestros días. En los últimos 24 años, desde la presidencia de John F. Kennedy hasta la administración Reagan, no se puede hablar de supremacía de uno u otro partido. En lo que va de esta etapa, los presidentes se han dedicado únicamente a "administrar la crisis". ${ }^{3}$

Acerca de la continuidad y discontinuidad del sistema bipartidista, se advierte de manera inmediata algo que asombra a cualquiera: su gran estabilidad. En casi ya 200 años de vida constitucional apenas si el sistema ha sufrido una modificación de fondo. Si bien uno de los partidos ha tenido casi siempre la preeminencia, el sistema bipartidista ha podido sostenerse como tal. ${ }^{14}$

Dada la rápida y sólida institucionalización de los dos grandes partidos difícilmente se ve que a finales del siglo $X I X$ aparece un partido populista y más tarde, en la segunda década de este siglo, uno progresista, sin llegar nunca a amenazar seriamente al bipartidismo. Hay varias razones para ello: el costo de montar una maquinaria equiparable a las de los grandes, la habilidad de los dos partidos para mediatizar las demandas y programas de terceros hasta llegar a hacerlos innecesarios. Otra razón tiene que ver con el "consenso". como se ha dicho ya antes, que se ha creado en torno a los programas bipartidistas, cuya explicación se tratará más adelante. cuando se hable del bloque ideológico que queda plasmado en la Constitución y de su primer desarrollo histórico. Cuando examinemos algunas de las dificultades para referirse a dos partidos con distintos programas ideológicos. señalaremos cómo, de acuerdo a la lógica de la Constitución de 1787, se convierten en partidos-foros-electorales de participación popular indirecta en las decisiones claves del gobierno. ${ }^{15}$

Ya se dijo que a primera vista se observa en el sistema político norteamericano una gran estabilidad. Sin embargo si se mira con un poco más de detenimiento, se advierten dos rupturas, una de carácter más bien nacional y otra con implicaciones claramente internacionales. La guerra civil señala el primer gran rompimiento del sistema bipartidista, cuando ambos partidos pierden el consenso en torno al problema de la esclavitud. Hasta el momento previo a la guerra civil, el sistema bipartidista había podido mantener la conciliación sugerida en la Constitución de conservar siempre el equilibrio de fuerzas. Con la guerra civil, el bipartidismo se transforma en una guerra campal entre bandos con distintos intereses, de un lado los agrario-mercantiles y

13 Luis Maira. "EE.UU.: ¿Un modelo agotado? las elecciones y el proyecto nacional" en Nueva Sociedad. Caracas. noviembre/diciembre de 1983, núm. 69, p. 96-102.

14 Salvo los 12 años iniciales federalistas $(\$ 789-1800)$, el partido republicano demócrata domina casi los siguientes 50 años (1801-1860). lo sigue el republicano con un periodo similar de hegemonía (1861-1933) hasta que el partido demócrata vuelve a dominar por un lapso de 36 años (1933-1969). con él se inicia la última etapa de alternancia partidista en el poder; los periodos más breves hasta ahora han sido el inicial y el último que se caracteriza por la incertidumbre y las grandes interrogantes.

15 La idea del partido como foro electoral que no posee principios bien diferenciados queda plásticamente descrita por el historiador Faulkner, al compararlo con botellas: "cada una lleva una etiqueta diciendo qué clase de licor contiene, pero ambas están vacías". Harold, U. Faulkner. et al., Vida del pueblo norteamericano, México. FCE, 1941. p. 236. 
del otro los agrario-industriales. La guerra civil pone en evidencia la incapacidad del bipartidismo para resolver un problema fundamental ya planteado desde los orígenes de la nueva nación: el desarrollo de dos tipos de economía. dentro del mismo marco de una economía liberal capitalista, en el que la pujanza de una de ellas termina por desplazar a la otra. El consenso ideológico-político no bastó para resolver pacíficamente la contienda y mantener ese difícil equilibrio de intereses. Esta ruptura no querida aunque previsible, significó especialmente la reconstitución del partido demócrata (el perdedor), que hubo de encontrar su nueva clientela en aquellos sectores no considerados por los republicanos: el nuevo proletariado urbano que acompañaba al gran desarrollo industrial del último cuarto de siglo, y la gran población negra que. liberada de las cadenas de la esclavitud, quedó como uno de los problemas sociales y políticos graves de un sistema social cimentado cada vez más en los entornos urbano-industriales.

En el plano ideológico, terreno todavía más difícil de precisar, ya no sólo en el campo de la pugna entre dos tipos de propiedad que rigieron hasta la década de los años sesenta del siglo XIX. el "crack" del 29 es un parteaguas en la historia política norteamericana. Desde 1789 hasta 1929 se puede afirmar sin temor a equivocarse que el sistema bipartidista está dominado por una misma ideología. Entre los contendientes existe un acuerdo explícito, cuando no al menos tácito, en relación a la defensa de la propiedad privada y sobre ésta, la de la libertad individual. Así, habría que referirse, aunque no de manera exclusiva, a la lucha bipartidista como una pugna entre dos corrientes de opinión de una misma tradición liberal, como bien lo señala el historiador Richard Hofstadter. El mismo autor observa que ante la gran depresión económica del 29. que implicó una crisis profunda de pérdida de los valores del individualismo debido a la creciente intervención del estado en la economía, surge un Roosevelt llevando en la mano un proyecto de corte paternalista, rehacedor de la ideología, en el que la personalidad presidencial ha de llenar el vacio de la pérdida de los valores liberales tradicionales. El proyecto denominado "New Deal" logra llenarlo hasta los años sesenta, década de la reinstauración de la crisis. Dejados atrás los valores tradicionales. ausentes de una personalidad y un proyecto coherente como el de Franklin D. Roosevelt, se planta la crisis ante al futuro. ${ }^{10}$

\section{III}

Si bien es cierto que el bipartidismo ha servido de base a la estabilidad y legitimación del sistema político norteamericano, el fundamento de esta peculiaridad bipartidista debe buscarse en las discusiones que rodean a la redacción y ratificación de la Constitución de 1789. Se da por sentado el hecho de que la carta constituyente significó todo un éxito desde el punto de vista político. Estableció un mecanismo jurídico de "pesos y contrapesos" que por un lado dejaba abierto el desarrollo de la libertad individual fincada en la propiedad de bienes, y por el otro tenía la capacidad de frenar los abusos inherentes al "impulso natural" de poseerlos.

Sin entrar en mayores detalles se puede decir que los constituyentes establecen un mecanismo normativo con un objetivo doble. En primer término, gobernarse a sí mismo sin destruirse en ese estado de guerra natural que es el comercio y, en segundo lugar, determinar los lineamientos que les permitan gobernar al resto social, a la gran masa analfabeta y sucia de pequeños

16 Richard Hofstadter, La tradición política norteamericana y los hombres que la formaron, op. cit., p. 8. 
granjeros, artesanos y, en general gente de pocos bienes. Como concesión al ciudadano común y a fin de poder consequir la ratificación de la Constitución por parte de las legislaturas locales, accederán los constituyentes a incluir a modo de enmiendas la carta de los Derechos Ciudadanos. La ratificación estatal es un punto crucial que contribuye a la legitimación de la Constitución como proyecto político nacional.

El arranque constitucional de la nación norteamericana presenta ya una de las paradojas no resueltas de su democracia. Sus fundadores temian de raíz a la democracia entendida como la participación directa de la muchedumbre en la ciencia del gobierno. Estaban convencidos de que era la democracia en si la que amenazaba la libertad $y$ es que. coinciden Charles $A$. Beard y Hofstadter, en sus mentes no estaba ligado el concepto de libertad al de democracia, sino al de la propiedad y sus privilegios. Los constituyentes se habían reunido en Filadelfia por iniciativa de Alexander Hamilton con el fin de poner término a la situación anárquica que la Confederación había propiciado. Frente a los artículos de la Confederación los constituyentes no luchaban por la libertad de comercio, sino por su regulación. En esto estaban más cerca de los mercantilistas que de Adam Smith. Tampoco estaban dispuestos a ofrecer libre acceso a las tierras desocupadas. Luchaban por la libertad. pero dosificada de acuerdo a intereses previamente establecidos. Por ejemplo, de los 55 constituyentes, por lo menos 14 especulaban con tierras y defendían el derecho de los propietarios ausentes y aún el de los especuladores: lo que pretendía la oligarquía constituyente era en realidad verse libre de la incertidumbre económica, de la normalidad monetaria, de la guerra comercial entre los nuevos estados, de la discriminación económica por parte de los gobiernos extranjeros, de los ataques a la clase acreedora y a la propiedad, $y$ de las insurrecciones populares. ${ }^{17}$ Siendo un grupo compacto frente a la defensa de la propiedad, los constituyentes presentarán, sin embargo. una pequeña fisura que dará origen al sistema bipartidista.

El surgimiento de los partidos políticos fue un hecho involuntario, no deseado por los constituyentes. La intención de la convocatoria era encontrar la fórmula adecuada para una "unión más perfecta" entre los diferentes estados, la alianza intersectorial de los grandes plantadores del sur orientados al monocultivo para el mercado externo, y los comerciantes, inversionistas $y$ fabricantes del noroeste. Entre los 55 miembros del constituyente sólo había un representante del sector agrícola del interior. Beard sugiere que si este sector hubiera tenido acceso a votar, la Constitución nunca hubiera sido aprobada. ${ }^{18}$

Es a este grupo de los 55 a quien no interesa un posible bipartidismo o la desunión, y menos el "multipartidismo" que regía en la época de la Confederación. Sin embargo, hay que anotar que en los poderes implícitos de la Constitución, en ese juego de impulsos y frenos, se dibujaba ya el margen inevitable de la lucha interpartidista.

James Madison, uno de los estadistas del constituyente con una visión más clara de las cosas, escribía en el número 10 de El Federalista que el origen más extendido de las facciones partidistas eran las diversas formas y la desigual distribución de la propiedad. Los intereses se agrupan, decía, alrededor de los que tienen y los que no, en torno a los que son deudores y los

17 Ibid., p. 15-16, 22-23. Entre los especuladores están incluidos Washington, Franklin, Gallatin. Patrick Henry, Robert Morris y James Wilson. Charles A. Beard, Una interpretación económica de la Constitución de los Estados Unidos. Buenos Aires. Arayú. 1953, p. 49-50.

18 Beard. op. cit., p. 101,p. 235-248. El autor amplía el análisis en el capítulo IV. "Garantías para la propiedad en la elección de convencionales." p. 63-71. 
que son acreedores, a los que tienen interés en la renta del suelo, en la manufactura o en el comercio. ${ }^{19}$ Acepta que este hecho conlleva la división de la sociedad en clases, con sus distintas perspectivas.

La función del gobierno, de acuerdo con Madison, será la de regular los distintos intereses, lo cual implica aceptar la formación de partidos y su participación directa en los asuntos de gobierno. Los más perspicaces, como Madison, sabían por experiencia que en una economía dominada por el mercado había intereses encontrados.

Supuesto lo anterior, en el sentido de que la aparición de los partidos tiene lugar debido a los poderes implícitos en la Constitución, lo que importa destacar es que los interesados son los que anteceden al texto y no viceversa.

Históricamente, antes de la contienda electoral, se establece la lucha real en torno a las estrategias politicas de gobierno, y relacionado estrechamente con esto, la lucha entre los diversos grupos de la sociedad. Se trata de dos niveles indisolubles. La vida de los partidos políticos en sociedades como la norteamericana no se entiende sin la dialéctica elites-masas. La elite además de defender sus propios intereses tiene que ver y canalizar, controlar o mediatizar los intereses de las mayorías, con o sin voto, según el momento histórico. Esta dialéctica tiene su propia evolución en el interior de los partidos. Una línea económica dura como la que proponía Hamilton no se entiende sin la visión populista de Jefferson. Así los partidos políticos nacen en el momento de la consumación de una revolución democrático-burguesa (democracia restringida a los propietarios y condicionada a los "sin tierra") con una doble función, por un lado, la de resguardar el orden establecido en la Constitución y, por el otro, de responder a las demandas populares de esa gran masa que espera llegar a convertirse en propietaria y, en consecuencia. de alcanzar la "libertad". Ya anteriormente se había hecho mención que el partido de los constituyentes (Hamilton y los federalistas) a fin de obtener la ratificación mínima por parte de 9 de los 13 estados, se ven obligados a incluir como parte de las primeras enmiendas unas Declaraciones sobre derechos ciudadanos. Es la concesión de la elite constituyente a los intereses del "hombre común". En el campo social la "rebelión del whiskey" de Daniel Shays en contra de la política arancelaria de Hamilton, será aprovechada por Jefferson para presentarse como candidato de oposición en 1796.

De hecho, desaparecido el gobierno británico, se reanuda la lucha tradicional colonial entre labradores. deudores y colonos por un lado, y comerciantes, inversionistas y grandes terratenientes por el otro. Es este último grupo, como se ha dicho, el que se aboca a una nueva constitución a fin de restablecer un orden que dé garantías a sus intereses comerciales y posibilite la ampliación del capital agrario con base en la propiedad y la especulación de tierras.

Se busca, pues, volver al estado de cosas prevalecientes antes de la independencia, pero sin tener que rendir tributo a la metrópoli. En ese sentido es cierto lo que señala el historiador William A. Williams en su obra Contours of american history al decir que la revolución remarcó la idea del mercantilismo en Norteamérica y que la Constitución está escrita desde esa perspectiva. En esa medida el texto constitucional se orientó a fundar un sistema económico y político nacional que sirviera de cimiento a un desarrollo en constante expansión. ${ }^{20}$

Si aceptamos lo antedicho, resulta entonces que la "unión más perfecta" lograda al ratificar la Constitución, se dirigía a beneficiar a un grupo minori-

19 Hamilton, Madison y Jay, El Federalista, México, FCE, 1974, (1 a. reimpresión), p. 37-41.

20 William A. Williams. The Contours of American History. Cleveland, Ohio. World, 1961 
tario y que a la hora de la práctica, la "unión" resultaba no ser "tan fuerte". En efecto, la alianza norte-sur es desanuda al comienzo mismo de la primera administración de Washington cuando Hamilton, secretario del Tesoro, da a conocer su programa financiero. A grandes rasgos, el programa se dirigía a tratar de sanear la economía nacional reconociendo la deuda externa así como la de los acreedores que habian financiado la guerra de independencia; establecía algunos aranceles e impuestos a ciertos productos como la destilación de alcoholes. Los más afectados por estas medidas eran los agricultores del interior que dependian de la destilación de sus granos para su comercialización y en segundo lugar, los plantadores del sur que tenían que comprar ahora más caro artículos tales como herramientas, que llegaban del exterior. Así, mientras apoyaban un gobierno central fuerte, entraban en contradicción con él. Para los agricultores del interior convenían, en cambio, gobiernos locales más fuertes que facilitaran la expedición amplia de papel moneda. mediante el cual podrían cubrir sus deudas.

El debate sobre la creación de un banco central es la ocasión que da nacimiento a un partido de oposición: el partido antifederalista o republicano jeffersoniano. Desmembrado el grupo constituyente, se sitúa el nuevo partido en el flanco de los intereses agrarios frente al grupo de los comerciantes $y$ navieros del norte.

La figura de Thomas Jefferson expresa, mejor que ninguna, otra de las paradojas que explican una "unión americana" cimentada sobre intereses locales y regionales, más que sobre un proyecto realmente nacional. Es decir, explica el carácter no clasista del bipartidismo norteamericano. Si bien Jefferson en los albores de la república se erige como el representante de los intereses agrarios, en la práctica - con una política proteccionista, expansionista y guerrera - tenderá a favorecer los intereses fabriles y comerciales representados por la misma oposición. La eficacia de esta política dual muestra que en un lapso menor de 20 años el bipartidismo perdió toda vigencia. A tal grado no eran opuestas en los sustancial la visión republicana y la federalista, que al final de ese periodo llegó a ser casi imposible diferenciarlas. Jefferson había comenzado su mandato presidencial declarando: "Todos somos republicanos, todos somos federalistas." Lo que sucedía era que hasta ese momento las dos facciones representaban sólo dos tipos de propiedad paralelas, a la vez que complementarias. Al final de dicho periodo se puede decir que los Estados Unidos de América han puesto los cimientos del desarrollo de la industria y de la consolidación de un mercado interno. fundados todavía en una sociedad eminentemente agraria. Henry Adams decía que "la industria norteamericana debía más a Jefferson que a cualquier estadista del norte, que no hicieron sino impulsarla cuando ya estaba creada". ${ }^{21}$ En todo caso, la democracia jeffersoniana había sentado las bases de la transición entre la generación de la oligarquía fundadora y la siguiente.

La compra de la Luisiana en 1803, que duplica el territorio norteamericano, y la guerra de 1812 contra Inglaterra fueron dos factores que determinarían el resurgimiento del bipartidismo o, en otras palabras, la recomposición de las fuerzas sociales. Terminada la guerra, saldadas las cuentas con Europa y fortalecida la industria nacional en la costa del noroeste, sus representantes están a favor de una tarifa arancelaria elevada, así como ven la necesidad de mayor mano de obra asalariada, debido a lo cual especulan con los nuevos territorios al oeste, por lo cual aumentan el valor de las tierras a fin de detener a los posibles asalariados inmigrantes. Al mismo tiempo, exigen un banco central fuerte que uniforme el valor de la moneda. En cuanto a los

21 Hofstadter, op. cit., p. 55. 
plantadores del sur, con la rápida expansión del algodón, ven en las regiones del oeste la posibilidad de extenderse y están a favor de tarifas bajas para comprar bienes nacionales o importados más baratos. El granjero, a su vez. requiere también los mismos productos industriales, pero quiere además dinero barato a fin de poder amortizar sus deudas y pugna por la ampliación y mejoramiento de caminos para la comercialización de sus productos.

En esta constelación de fuerzas, la región y el hombre de la frontera se iban convirtiendo en piezas clave del equilibrio de poderes entre las fuerzas de la economía sureña y la industrial-comercial del norte.

Se observan algunos cambios en el sistema bipartidista durante esta segunda fase. Desaparecido el partido federalista, resurge en 1824 como partido nacional republicano, diez años más tarde como partido Whig, $y$ en 1854 como el republicano de hoy en día. El partido antifederalista o republicano se transforma en el demócrata, identificado ahora con la figura de Andrew Jackson, el combatiente llegado precisamente de la frontera.

El transfondo social del arribo al poder de la democracia jacksoniana está enmarcado por la crisis y el pánico financiero de 1819 originado en la rápida expansión. especulación y proliferación de bancos no oficiales. Sobre todo en el oeste y en el sur los especuladores habian gastado todos sus recursos en la compra desenfrenada de tierras. La mayor parte había quedado endeudada y los acreedores no veían el modo de recuperar su dinero. No habiendo ya un partido de oposición. los deudores se organizan en torno a las legislaturas locales y consiguen la promulgación de moratorias. Por otro lado los bancos locales se enfrascan en una guerra fiscal con el Banco Central. Es el momento en la historia norteamericana en que por primera vez la gran población de agricultores ve la relación íntima entre la política y su propio bienestar.

Así pues. cabe señalar un cambio fundamental en esta fase que podría denominarse como la de la consolidación temprana del sistema bipartidista. La lucha partidista ya no se concentra en el Congreso sino en las alianzas interregionales orientadas casi exclusivamente a la lucha electoral. La llegada de Andrew Jackson a la presidencia en 1828 señala el fin de la dinastía de los fundadores y el comienzo del arribo a las asambleas electorales de mayor número de población. La llamada "revolución de 1828" aportó un relevo de personal más que un cambio de ideas y de programas. En la persona de Jackson, ahora ya no de un partido. se encontraba al mismo tiempo al deudor y al acreedor, al demócrata como al aristócrata. Hofstadter resume la situación de la siguiente manera: "a medida que los granjeros pobres y los trabajadores ganaban votaciones, fue surgiendo el tipo de político que sólo había existido en estado embrionario en la época de Jefferson; es decir, el técnico en conducción de masas, que sabe cómo alimentar los sentimientos de éstas". ${ }^{22}$ Este periodo simboliza pues la llegada de la clase media a las urnas electorales y a los puestos públicos. Esto no significaba en absoluto que la oligarquía hubiera dejado el poder: tan sólo tenía que compartirlo con esa clase en ascenso que desde la redacción de la Constitución tanto atemorizaba a sus acreedores; se estaba haciendo realidad aquello que Madison había previsto: "si contemplamos fríamente el asunto, dijo, los propietarios del país serán los más seguros depositarios de la libertad republicana. En el futuro, una gran mayoría del pueblo estará no sólo sin tierras, sino también sin ninguna suerte de propiedad. $Y$ entonces se unirán bajo la influencia de una situación común en cuyo caso los derechos de propiedad y las libertades públicas no reposarán seguras en sus manos, o, lo que es más probable, se

22 Ibid., p. 72 
convertirán en movimientos de opulencia y de la ambición, y en tal supuesto habrá igualmente peligro del otro lado". ${ }^{23}$

Con esto el círculo de la democracia norteamericana cimentada sobre el sistema bipartidista encuentra su redondez. Sustentada (la democracia) en un principio oligárquico y en una ideología liberal, contando con suficientes recursos naturales y humanos para su realización, aparece la masa con la posibilidad de ver realizado su sueño de ascenso en la escala política y social. Sin embargo, la misma redondez del círculo lleva consigo su vicio: la incapacidad orgánica para anular una dinámica de violencia y de desigualdad social. 